\title{
Clinical results and complications following surgical management of symptomatic os acromiale: a systematic review
}

\author{
Jennifer A. Purnell ${ }^{1}$, Jonathan Bourget-Murray ${ }^{1}$, Adam Kwapisz², Aaron J. Bois ${ }^{1}$ and Justin LeBlanc ${ }^{\text {** }}$
}

\begin{abstract}
Background: This review compares the outcomes and complication rates of three surgical strategies used for the management of symptomatic os acromiale. The purpose of this study was to help guide best practice recommendations.

Methods: A systematic review of nine prospective studies, seven retrospective studies, and three case studies published across ten countries between 1993 and 2018 was performed. Adult patients (i.e., $\geq 18$ years of age) with a symptomatic os acromiale that failed nonoperative management were included in this review. Surgical techniques utilized within the included studies include excision, acromioplasty, and open reduction and internal fixation (ORIF). The primary outcomes of interest included patient satisfaction. Range of motion and several standardized outcome measurement tools were also included in the final analysis.

Results: Patient satisfaction was highest in the excision and ORIF groups, with 92\% and 82\% of patients reporting good to excellent postoperative results, respectively, compared to $63 \%$ in the acromioplasty group. All three patient groups experienced improvements in postoperative outcomes (i.e., active range of motion and patientreported outcome scores). The excision group experienced a complication rate of $1 \%$, while the acromioplasty group experienced a complication rate of $11 \%$ and the ORIF group a rate of $67 \%$.

Conclusion: This study reports on the largest sample of patients who underwent surgical treatment for a symptomatic os acromiale. We have demonstrated that excision of the os with meticulous repair of the deltoid resulted in the best clinical outcomes with the least complications. In healthy adult patients with a large os fragment and a normal rotator cuff, surgical fixation may provide increased preservation of deltoid function while offering good to excellent patient satisfaction. However, patients must be informed that a second procedure may be required to remove symptomatic hardware.
\end{abstract}

Keywords: Os acromiale, Symptomatic, Surgical technique, Surgical outcomes, Complications

\section{Background}

An os acromiale represents a failure of osseous union between the secondary ossification centers of the acromion (i.e., acromial apophysis) and is present in approximately $8 \%$ of the population $[1,2]$. The majority of os acromiale cases are asymptomatic and are found incidentally; as a result, the true incidence of this shoulder problem is unknown. A small proportion of patients present with a painful shoulder that is attributed to inflammation at the

\footnotetext{
*Correspondence: justin.leblanc2@ucalgary.ca

'Department of Surgery, Section of Orthopaedic Surgery, University of

Calgary, Calgary, Alberta, Canada

Full list of author information is available at the end of the article
}

pseudarthrosis, impingement of the rotator cuff, or arthritic changes of the acromioclavicular joint secondary to hypermobility of the unfused bony segment [2].

A number of surgical techniques have been described for the treatment of symptomatic os acromiale including fragment excision [3-10], open or arthroscopic acromioplasty $[3,6,11]$, and open reduction and internal fixation (ORIF). A variety of fixation techniques have been reported with successful union and improvements in patient-reported outcome scores [12-21]. Currently, a universally accepted surgical technique to manage symptomatic os acromiale does not exist. In 2011, Harris et al. [22] systematically reviewed the radiographic and

(C) The Author(s). 2019 Open Access This article is distributed under the terms of the Creative Commons Attribution 4.0 International License (http://creativecommons.org/licenses/by/4.0/), which permits unrestricted use, distribution, and 
clinical outcomes of 115 patients (122 shoulders) that underwent surgical management of a symptomatic os acromiale. Since then, 9 additional studies (95 patients, 99 shoulders) have been published reporting the surgical results for symptomatic os acromiale. Despite such reports, a standard of care for the treatment of symptomatic os acromiale remains controversial.

At the present time, there is a paucity of high-level evidence supporting one surgical technique over another. The purpose of this systematic review was to compare the surgical outcomes and complications between three surgical techniques (i.e., fragment excision, acromioplasty, and ORIF) commonly used to manage symptomatic os acromiale. We hypothesize that patients will report comparable subjective outcomes following all surgical techniques. Furthermore, we anticipate an overall trend of improved objective outcome measures across all groups with the best results observed in the excision group. Additionally, we anticipate lower nonunion rates and higher complication rates when internal fixation is utilized.

\section{Methods}

\section{Literature search}

The present systematic review was performed in accordance with the Preferred Reporting Items for Systematic Reviews and Meta-Analyses (PRISMA) guidelines [23]. In January 2018, a comprehensive search for all level I-IV evidence published in the English literature using the online databases MEDLINE, PubMed, and Embase was performed. The purpose of this search was to identify eligible studies featuring postoperative patient-reported outcomes across patient groups managed by either surgical excision, acromioplasty, or surgical fixation (i.e., ORIF). The search terms "os acromial" and "os acromiale" were used to ensure all appropriate studies were captured. All relevant articles published up to and including June 2018 discussing the surgical management of symptomatic os acromiale in adult patients (i.e., $\geq 18$ years of age) were identified. All prospective or retrospective studies, non-randomized comparison studies, and case series were considered for inclusion. If more than one study was conducted at the same institution, the article that had the most complete or recent data was selected. Studies were excluded if they met the following criteria: (1) basic science studies (e.g., biomechanical studies); (2) reviews, clinical guidelines/expert opinions, and technique articles without patient data; and (3) conference abstracts and gray literature.

\section{Study selection}

The search strategy identified 308 studies as outlined in Fig. 1. Duplicates were identified and removed from our reference manager, EndNote (Thomas Reuters, New York, $\mathrm{NY}$ ). One hundred and thirty studies remained. All titles and abstracts were independently screened by two authors (JP and JBM) to determine study eligibility; there were no instances of disagreement between these two authors. This initial screen resulted in 31 studies that were subsequently retrieved (i.e., full-text manuscripts), independently reviewed, and accepted into the study if they met the inclusion criteria previously outlined. Of the 31 full-text manuscripts reviewed, 19 studies were

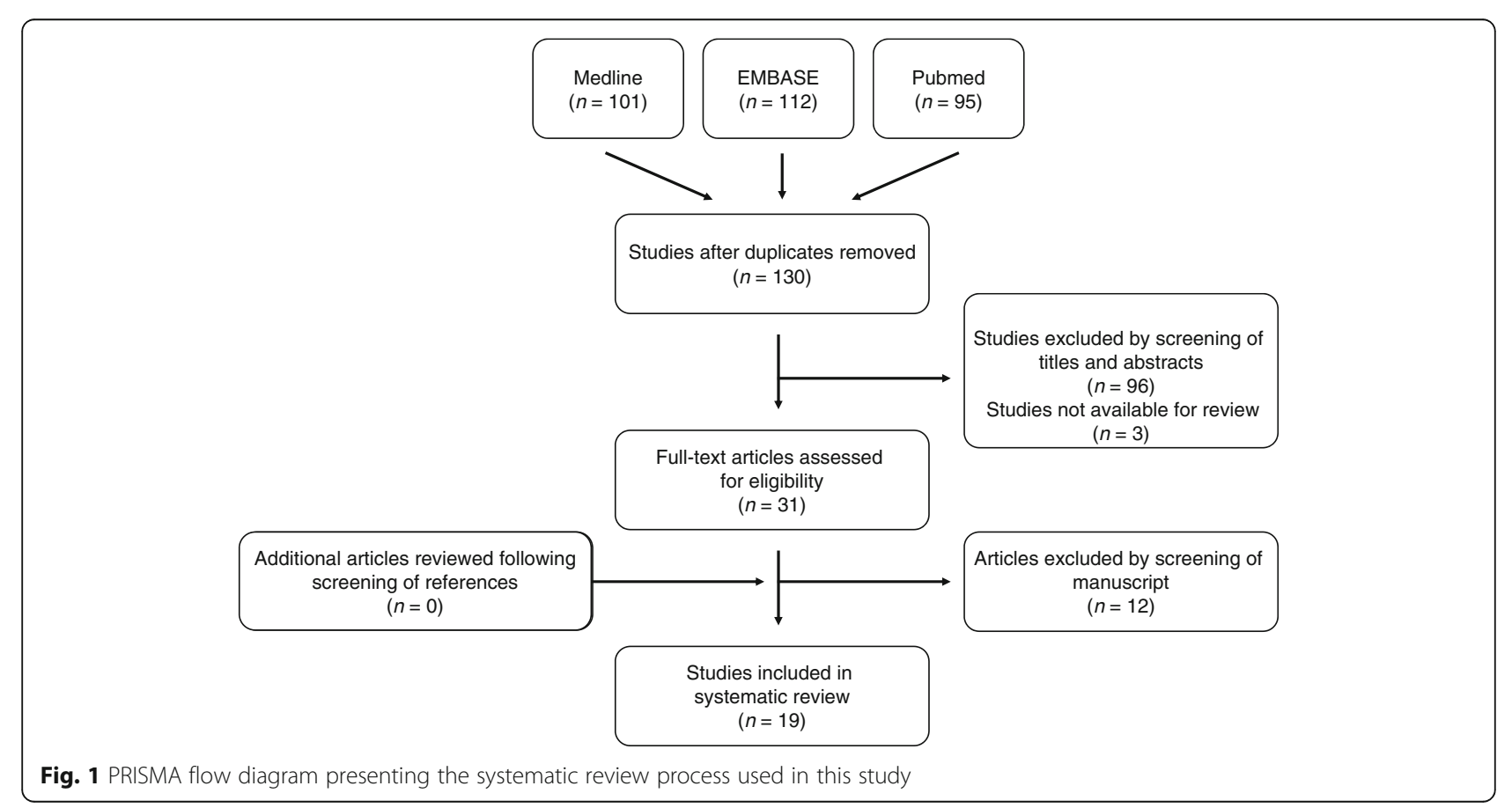


included for the final analysis. The reference lists of all 19 studies were cross-referenced to capture additional studies missed by our initial search; no other studies were identified.

\section{Data extraction}

Data extraction was performed by populating a predefined data abstraction sheet. This included the total number of patients and shoulders included in the study, number of female and male patients, average age of the patient cohort, hand dominance, os acromiale subtype (preacromion, mesoacromion, and meta-acromion), surgical procedure(s) performed, range of motion, patientreported outcome scores, and complications. Several standardized outcome measurement tools were used across studies, including the Constant score, American Shoulder and Elbow Surgeons (ASES) Shoulder Score, University of California Los Angeles (UCLA) Shoulder Score, Penn Shoulder Score (PSS), and the Disabilities of the Arm Shoulder and Hand (DASH) Score.

\section{Statistical analysis}

The summary statistics indicating the number of patients extracted from the individual studies was performed using counts, frequencies, and percentages where necessary. Data points are expressed as weighted means. A metaanalysis could not be performed due to the heterogeneity in data across studies, and as a result, no statistical tests were performed.

\section{Results}

Nineteen studies meeting the inclusion criteria were identified and included in our final analysis [3-21]. Collectively, these studies account for 210 patients, with a total of 221 shoulders that underwent 221 surgeries for a symptomatic os acromiale. The average age of the included patients was 46 years (range, 19 to 78 years). Excluding 7 patients in the study performed by Edelson et al. [5], where patient gender was not reported, $65 \%$ of patients in this review were male. Of the 99 cases that reported hand dominance, $64 \%$ of surgeries were performed on the patient's dominant arm. Of the 174 cases that reported the anatomical location of the os acromiale, 7 (4\%) involved the preacromion, $164(94 \%)$ the mesoacromion, and 3 (2\%) the meta-acromion. With regard to concurrent surgical procedures performed at the time of the index surgery, rotator cuff repair was performed in $56 \%$ of cases (38\% of patients within the excision group, $50 \%$ in the acromioplasty group, and $65 \%$ in the internal fixation group). In 9.5\% of patients, a biceps tenodesis was performed in addition to the procedure used to address the symptomatic os acromiale. The mean postoperative follow-up was 32.2 months (range, 5 to 120 months). All surgical techniques used to manage the symptomatic os acromiale resulted in improved clinical outcomes, as measured using both subjective and objective methods. Details of each included study are presented in Table 1 . All results are outlined in Tables 2 and 3.

\section{Excision}

Complete surgical excision of the os acromiale accounted for $35 \%$ of the included cases (77 of 221 cases) [3-10, 21]. A variety of objective outcome measures were used within the included studies, all of which demonstrated postoperative improvements (i.e., preoperative vs. postoperative scores). The mean ASES score improved from 43.3 to 92.1, Constant pain score from 3.9 to 12.9, UCLA score from 16.7 to 31.3, and Penn score from 50.6 to 78.5 (Table 2). Mean forward elevation improved by $10^{\circ}$ while no change was observed in external rotation. Ninety-two percent of patients rated their overall subjective postoperative outcome as "good" or "excellent" (Tables 2 and 3).

\section{Acromioplasty}

Acromioplasty accounted for only $8 \%$ of the included cases (18 of 221 cases) [3, 6, 11]. There was a mean improvement in the Constant pain score from 4.5 to 12.5 (i.e., preoperative vs. postoperative score) (Table 2). There were mean postoperative improvements in both forward elevation $\left(28^{\circ}\right)$ and external rotation $\left(9^{\circ}\right)$. Sixty-three percent of patients rated their overall subjective postoperative outcome as "good" or "excellent," $25 \%$ as "satisfactory," and $12 \%$ as "poor" (Tables 2 and 3).

\section{Open reduction and internal fixation}

Open reduction and internal fixation was the most frequently performed surgery, accounting for $57 \%$ of the included cases (126 of 221 cases) [3, 5, 11-21]. Procedures performed within this category included internal fixation using Kirshner wires $(n=57)[3,11,14,17]$, screws $(n=56)$ $[5,11,12,15,18-21]$, plates $(n=5)[16]$, and absorbable screws $(n=8)$ [13]. A tension band construct was most commonly utilized (100 of 113 cases; 88\%), whereby inter-fragmentary compression was obtained using two parallel Kirshner wires or cannulated screws combined with a cerclage or figure-of-eight wire $[3,11,12,14,15,17,21]$ or suture $[19,20]$. Sixty-seven patients in the fixation group (67 of 126 cases; 53\%) received autogenous bone grafting, while 1 subject received HEALOS injectable bone graft replacement (DePuy, Raynham, MA, USA) [19], and 8 subjects received tri-calcium phosphate bone substitute [13]. Therefore, the majority (76 of 126 cases; 60\%) of patients in the fixation cohort received concomitant autogenous bone graft or synthetic bone graft substitute.

When objective data was reported, there were improvements observed in active range of motion and patient-reported outcome scores (i.e., preoperative vs. postoperative scores) (Table 2). Specifically, the mean 
Table 1 Characteristics of the included studies

\begin{tabular}{|c|c|c|c|c|c|c|c|c|}
\hline Study & $\begin{array}{l}\text { No. of } \\
\text { patients }\end{array}$ & $\begin{array}{l}\text { No. of } \\
\text { shoulders }\end{array}$ & Male:female & $\begin{array}{l}\text { Mean age } \\
\text { (range) }\end{array}$ & $\begin{array}{l}\text { Dominant/non- } \\
\text { dominant }\end{array}$ & $\begin{array}{l}\text { Pre/Meso/ } \\
\text { Meta }\end{array}$ & $\begin{array}{l}\text { Mean follow-up } \\
\text { (months, range) }\end{array}$ & Surgical technique \\
\hline Edelson et al. 1993 [5] & 7 & 7 & NR & NR & NR & NR & $29(18-40)$ & $\begin{array}{l}5 \text { excision } \\
2 \text { ORIF (screws) }\end{array}$ \\
\hline Hutchinson et al. 1993 [6] & 3 & 3 & $1: 2$ & $24(18-27)$ & NR & NR & $15(6-24)$ & $\begin{array}{l}1 \text { excision } \\
2 \text { acromioplasty }\end{array}$ \\
\hline Hertel et al. 1998 [17] & 12 & 15 & 0 & $54(37-63)$ & $11: 4$ & 0/15/0 & $44(13-72)$ & 15 ORIF (K-wires) \\
\hline Warner et al. 1998 [21] & 14 & 15 & $7: 7$ & $57(19-76)$ & NR & $1 / 11 / 3$ & $34(24-47)$ & $\begin{array}{l}3 \text { excision } \\
3 \text { ORIF (K-wires) } \\
2 \text { excision following failed } \\
\text { ORIF (K-wires) } \\
7 \text { ORIF (screws) }\end{array}$ \\
\hline Ryu et al. 1999 [18] & 4 & 4 & $3: 1$ & $27(20-43)$ & $2: 2$ & $0 / 4 / 0$ & $34(12-84)$ & 4 ORIF (screws) \\
\hline Satterlee 1999 [20] & 6 & 6 & $4: 2$ & $48(29-63)$ & $3: 3$ & $0 / 6 / 0$ & $55(36-72)$ & 6 ORIF (screws) \\
\hline Wright et al. 2000 [10] & 12 & 13 & $8: 4$ & $36(18-54)$ & NR & $0 / 13 / 0$ & $29(20-72)$ & 13 excision \\
\hline Boehm et al. 2003 [3] & 33 & 33 & $23: 10$ & $56(44-70)$ & NR & $3 / 30 / 0$ & $41(24-95)$ & $\begin{array}{l}6 \text { excision } \\
5 \text { acromioplasty } \\
22 \text { ORIF (K-wires) }\end{array}$ \\
\hline Abboud et al. 2006 [11] & 19 & 19 & $12: 7$ & $53(35-73)$ & $13: 6$ & 0/19/0 & $40(24-94)$ & $\begin{array}{l}11 \text { acromioplasty } \\
5 \text { ORIF (K-wires) } \\
3 \text { ORIF (screws) }\end{array}$ \\
\hline Pagnani et al. 2006 [9] & 9 & 11 & $9: 0$ & $22(18-25)$ & $7: 4$ & 0/11/0 & $44(24-78)$ & 11 excision \\
\hline Sahajpal et al. 2007 [19] & 1 & 1 & $0: 1$ & 53 & $1: 0$ & $0 / 1 / 0$ & 18 & 1 ORIF (screws) \\
\hline Bedi et al. 2009 [15] & 1 & 1 & $0: 1$ & 19 & $0: 1$ & $0 / 1 / 0$ & 12 & 1 ORIF (screws) \\
\hline Campbell et al. 2012 [4] & 28 & 31 & $17: 11$ & $55(21-78)$ & 18:10 & $3 / 28 / 0$ & $41(9-85)$ & 31 excision \\
\hline Atoun et al. 2012 [13] & 8 & 8 & $1: 7$ & $54(38-67)$ & $6: 2$ & 0/8/0 & $22(12-36)$ & 8 ORIF (absorbable screws) \\
\hline Barbier et al. 2013 [14] & 10 & 10 & $7: 3$ & $43(16-65)$ & NR & 0/10/0 & $48(6-124)$ & 10 ORIF (K-wires) \\
\hline Johnston et al. 2013 [7] & 6 & 6 & $4: 2$ & $53(36-65)$ & $3: 3$ & $0 / 6 / 0$ & $25(5-36)$ & 6 excision \\
\hline Kawaguchi et al. 2016 [8] & 1 & 1 & $0: 1$ & 73 & $0: 1$ & $0 / 1 / 0$ & 27 & 1 excision \\
\hline Beliën et al. 2017 [16] & 5 & 5 & $4: 1$ & $49(20-67)$ & NR & NR & $7.5(5-13)$ & 5 ORIF (plating) \\
\hline Atinga et al. 2018 [12] & 31 & 32 & $24: 7$ & $50(21-74)$ & NR & NR & $47(12-120)$ & 32 ORIF (screws) \\
\hline
\end{tabular}

NR not reported, Pre preacromion, Meso mesoacromion, Meta meta-acromion, ORIF open reduction and internal fixation

${ }^{\dagger}$ Several patients underwent surgical management for symptomatic bilateral os acromiale

ASES score improved from 38.8 to 93.1, Constant pain score from 4.5 to 13.1 , Constant total score 52.5 to 76.1, and UCLA score from 19 to 35 (Table 2). Mean improvements in active forward elevation and external rotation were $30^{\circ}$ and $1.5^{\circ}$, respectively (Table 3 ). Eighty-two percent of patients rated their overall subjective postoperative outcome as "good" or "excellent."

\section{Complications}

A detailed description of complication type stratified by surgical category is presented in Table 4 . There was a total of 87 reported complications among the three treatment categories studied. The excision group experienced a single surgical site infection that required reoperation (irrigation and debridement). The acromioplasty group experienced 2 deep surgical site infections requiring reoperation (irrigation and debridement). The ORIF group, in comparison, experienced a complication rate of $67 \%$ (84 of 126). Of the 84 reported complications in this treatment category, however, 34 (40.5\%) were attributed to asymptomatic hardware removal. Of the 8 bio-absorbable screw fixation cases, there were 4 reported complications (1 nonunion, 2 symptomatic hardware, 1 iatrogenic fracture); of these patients, 2 required reoperation to trim the screws (i.e., decrease hardware prominence), 6 months after the first procedure. Patients that underwent plate fixation $(n=5)$ experienced 2 complications (i.e., symptomatic hardware), both requiring removal. There were 19 complications reported in those patients managed with cannulated screws including 1 nonunion, 1 surgical site infection requiring reoperation, 1 superficial wound dehiscence, 1 seroma formation, and 15 reoperations for hardware removal (Table 4). There was a total of 59 reported complications in patients managed with K-wires including 1 deep surgical site infection requiring reoperation, 2 superficial surgical site infections managed medically, 2 surgical failures (symptomatic nonunion) requiring revision surgery (i.e., fragment 
Table 2 Patient-reported outcome scores stratified by surgical category

\begin{tabular}{|c|c|c|c|c|c|c|c|c|}
\hline \multirow[t]{2}{*}{ Surgical technique } & \multirow{2}{*}{$\begin{array}{l}\text { No. of } \\
\text { patients }\end{array}$} & \multirow{2}{*}{$\begin{array}{l}\text { No. of } \\
\text { shoulders }\end{array}$} & \multicolumn{5}{|c|}{ Patient-reported outcome scores } & \multirow{2}{*}{$\begin{array}{l}\text { Subjective scores } \\
\text { Good or excellent (\%) }\end{array}$} \\
\hline & & & Score & No. of patients ${ }^{\dagger}$ & Preop* & Postop* & Change $^{\ddagger}$ & \\
\hline \multirow[t]{6}{*}{ Excision } & 71 & 77 & ASES & 31 & 43.3 & 92.1 & 48.8 & \\
\hline & & & Constant pain component & 11 & 3.9 & 12.9 & 9.0 & \\
\hline & & & Constant total & 11 & NR & 72.6 & --- & $92 \%$ (59 of 64 responses) \\
\hline & & & UCLA & 14 & 16.8 & 31.3 & 14.5 & \\
\hline & & & PSS & 6 & 50.6 & 78.5 & 27.9 & \\
\hline & & & QuickDASH & 6 & NR & 15.9 & --- & \\
\hline \multirow[t]{2}{*}{ Acromioplasty } & 18 & 18 & Constant pain component & 18 & 4.5 & 12.5 & 8.0 & $63 \%$ (10 of 16 responses) \\
\hline & & & Constant total & 18 & NR & 73.9 & --- & \\
\hline \multirow[t]{6}{*}{ ORIF } & 121 & 126 & ASES & 6 & 38.8 & 93.1 & 54.3 & \\
\hline & & & Constant pain component & 22 & 4.5 & 13.1 & 8.6 & \\
\hline & & & Constant total & 45 & 52.5 & 76.1 & 23.6 & \\
\hline & & & UCLA & 4 & 19 & 35 & 16 & \\
\hline & & & DASH & 5 & NR & 37.3 & --- & $82 \%$ (54 of 66 responses) \\
\hline & & & QuickDASH & 10 & NR & 20.6 & --- & \\
\hline
\end{tabular}

ORIF open reduction and internal fixation, Preop preoperative, Postop postoperative, ASES American Shoulder and Elbow Society, UCLA University of California Los Angeles, DASH Disabilities of Arm Shoulder and Hand, PSS Penn shoulder score, "---" change score not calculated

${ }^{\dagger}$ Number of patients that completed patient-reported outcome scores within each category of surgical treatment

*The values are given as weighted means

${ }^{\ddagger}$ Postoperative score minus preoperative score

excision), 8 radiographic nonunions managed conservatively, 2 cases of complex regional pain syndrome, and 44 reoperations for hardware removal (Table 4).

\section{Discussion}

Operative management is often recommended for patients with a symptomatic os acromiale that have failed nonoperative treatment. A variety of surgical techniques are available; however, a universally accepted standard of treatment does not exist. In light of the current literature, best practice recommendations remain unclear and evidence-based recommendations are lacking.

Several surgical strategies have been described for the treatment of a symptomatic os acromiale. Excision has been described for both small $(<1.5 \mathrm{~cm})$ and large $(>1.5)$ fragments, both with and without deltoid repair. Neer and colleagues [24] have reported generally poor outcomes and weakened deltoid performance following large acromion fragment excision given that it alters the fulcrum needed for deltoid function; careful repair of the deltoid attachment following os acromiale excision leads to improved patient outcomes [24, 25]. All nine studies included in this review, in which excision was undertaken, employed a deltoid-sparing or repair technique to ensure postoperative deltoid function would not be compromised. The success seen following acromioplasty (i.e., subtotal excision) is often attributed to the reduction of bony impingement secondary to the mobility of the os fragment. Determining the amount of mobility across the os fragment is difficult to quantify clinically, and as such, selecting patients who would benefit from an acromioplasty remains difficult. The use of ORIF has been previously described in the literature; greater

Table 3 Active range of motion stratified by surgical category

\begin{tabular}{|c|c|c|c|c|c|c|c|c|}
\hline \multirow[t]{2}{*}{ Surgical technique } & \multirow[t]{2}{*}{ No. of patients } & \multirow[t]{2}{*}{ No. of shoulders } & \multicolumn{6}{|c|}{ Range of motion (mean, range) } \\
\hline & & & FE Preop & FE Postop & Change $^{\dagger}$ & ER Preop & ER Postop & $\overline{\text { Change }^{\dagger}}$ \\
\hline Excision & 71 & 77 & $\begin{array}{l}156.5(143-170) \\
(n=7)^{*}\end{array}$ & $\begin{array}{l}166.5(163-170) \\
(n=7)^{*}\end{array}$ & 10 & $\begin{array}{l}70(70) \\
(n=1)^{*}\end{array}$ & $\begin{array}{l}70(70) \\
(n=1)^{*}\end{array}$ & 0 \\
\hline Acromioplasty & 18 & 18 & $\begin{array}{l}117(102-132) \\
(n=11)^{*}\end{array}$ & $\begin{array}{l}145.3(134-152) \\
(n=18)^{*}\end{array}$ & 28.3 & $\begin{array}{l}33.3(22.5-44) \\
(n=11)^{*}\end{array}$ & $\begin{array}{l}42(35-46) \\
(n=18)^{*}\end{array}$ & 8.7 \\
\hline ORIF & 121 & 126 & $\begin{array}{l}125.7(116-144.5) \\
(n=24)^{*}\end{array}$ & $\begin{array}{l}155.7(141-165) \\
(n=24)^{*}\end{array}$ & 30 & $\begin{array}{l}53(38-61) \\
(n=24)^{*}\end{array}$ & $\begin{array}{l}54.5(37-64.5) \\
(n=24)^{*}\end{array}$ & 1.5 \\
\hline
\end{tabular}

The values are presented in degrees (weighted means, range)

ORIF open reduction and internal fixation, FE forward elevation, ER external rotation, Preop preoperative, Postop postoperative

*The number of patients with available data

${ }^{\dagger}$ Postoperative score minus preoperative score 
Table 4 A detailed description of complication type stratified by surgical category

\begin{tabular}{|c|c|c|c|c|c|c|c|}
\hline \multirow[t]{2}{*}{ Complication } & \multirow{2}{*}{$\begin{array}{l}\text { Excision } \\
(n=77)\end{array}$} & \multirow{2}{*}{$\begin{array}{l}\text { Acromioplasty } \\
(n=18)\end{array}$} & \multicolumn{5}{|l|}{ ORIF } \\
\hline & & & $\begin{array}{l}\text { K-wires } \\
(n=57)\end{array}$ & $\begin{array}{l}\text { Cannulated screws } \\
(n=56)\end{array}$ & $\begin{array}{l}\text { Plating } \\
(n=5)\end{array}$ & $\begin{array}{l}\text { Absorbable screws } \\
(n=8)\end{array}$ & Total \\
\hline Seroma & & & & 1 & & & 1 \\
\hline Wound dehiscence & & & & 1 & & & 1 \\
\hline Surgical site infection & 1 & 2 & 3 & 1 & & & 7 \\
\hline Failure of index procedure & & & 2 & & & & 2 \\
\hline Nonunion & & & 8 & 1 & & 1 & 10 \\
\hline latrogenic fracture & & & & & & 1 & 1 \\
\hline Symptomatic hardware removal & & & 20 & 5 & 2 & 2 & 29 \\
\hline Asymptomatic hardware removal & & & 24 & 10 & & & 34 \\
\hline Complex regional pain syndrome & & & 2 & & & & 2 \\
\hline Total & 1 & 2 & 59 & 19 & 2 & 4 & 87 \\
\hline
\end{tabular}

ORIF open reduction and internal fixation

union rates and fewer hardware removals can be seen with the use of cannulated screws compared to K-wire fixation.This is attributed to cannulated screws providing superior interfragmentary compression and a more rigid construct (vs. K-wires). Overall, ORIF techniques are performed in such a way that the acromion length and deltoid attachments are preserved, thereby maintaining deltoid strength and function.

All studies included in this review reported improved active range of motion following surgery. Forward elevation and external rotation improved across all treatment groups with the exception of external rotation in the excision group which remained unchanged. The most pronounced improvements in forward elevation were observed in both acromioplasty and ORIF treatment groups, while improvements in external rotation were greatest following acromioplasty.

Given the heterogeneity of standardized outcome scoring systems used across studies, it was difficult to directly compare the results between surgical groups. However, we can assess the results from each score individually using the previously published minimal clinically important difference (MCID) scores. Wylie et al. [26] report a MCID of 17 for the ASES score and 11.4 for the PSS when applied to rotator cuff pathologies and impingement. The excision and ORIF groups exceed the MCID for the ASES score, while both the acromioplasty and ORIF groups exceed the MCID for the PSS. The ORIF group demonstrated an improved postoperative Constant score of 23.5 points which is considered a clinically significant improvement [27]. Unfortunately, the UCLA score does not have published MCID data; however, we report improvements in postoperative scores using the UCLA system for both groups of patients who underwent excision and ORIF. Therefore, using these MCID scores, we can comfortably suggest that all three of the above surgical techniques lead to clinically relevant improvements in objective patient outcomes. Patient subjective outcomes across all included studies classified postoperative satisfaction into four categories of poor, fair, good, and excellent. The highest patient satisfaction rate was experienced by the excision group (92\%), closely followed by the fixation group (82\%). The acromioplasty group demonstrated good or excellent satisfaction in only $63 \%$ of patients; the remainder of patients reported fair or poor outcomes, which may be partly explained by a persistently painful nonunion.

When comparing complication rates, it is clear that ORIF carries the highest risk of complication with a reported $67 \%$ event rate. Of these, $40.5 \%$ were for asymptomatic hardware. Although potentially not considered a "true" postoperative complication, hardware removal does come with potential risks to the patient and adds significant cost to the health care system. Screw fixation accounted for $20 \%$ of symptomatic hardware requiring removal, while K-wire fixation accounted for the remainder. Within the ORIF group, the use of cannulated screws carries a lower overall complication rate (19 complications in 56 cannulated screw cases) whereby K-wire fixation carries the highest complication rate (59 complications in $57 \mathrm{~K}$-wire cases). In addition, we report a $14 \%$ (8 of 57 cases) incidence of nonunion in patients treated with $\mathrm{K}$-wire fixation compared to $2 \%$ ( 1 of 56 cases) in those treated with cannulated screws. Union was assessed radiographically at 6 months postoperatively. Nonunion is an important determinant of surgical outcome as it has been noted to be a primary cause of continued pain and patient dissatisfaction despite operative management [13].

This review is not without its limitations, specifically that it is fundamentally limited by the weaknesses of each included study. Sources of bias in this study include (1) small number of cases per study (and within 
treatment groups), (2) substantial heterogeneity in reported outcome scores, (3) disease-specific outcome scores do not exist for patients with symptomatic os acromiale, (4) performance bias resulting from the use of concomitant surgical interventions (i.e., rotator cuff repair, bone grafting) as well as technique variation across surgeons (most apparent within the ORIF group), and (5) short-term clinical follow-up. Furthermore, due to the retrospective nature of the included studies, the overall strength of the clinical recommendations was limited.

\section{Conclusions}

This study reports on the largest sample of patients to date that have undergone surgical treatment for a symptomatic os acromiale. Excision of the os acromiale fragment with meticulous repair of the deltoid attachment leads to the greatest patient satisfaction while providing improvement in objective outcome measures and imparting the lowest risk of postoperative complications. This method of treatment may provide more consistent results in patients with small symptomatic os acromiale fragments (i.e., preacromial os); however, this review has demonstrated that excision of larger fragments (i.e., mesoacromial) can provide good to excellent surgical results. The role of acromioplasty (i.e., subtotal os excision) remains unclear, but is likely best reserved for patients with a stable symptomatic os and an associated rotator cuff tear that is addressed at the same time as the subacromial decompression. Similar to fragment excision, this method of treatment has a low complication risk. In patients with a large unstable fragment (i.e., mesoacromion) with limited or no rotator cuff disease, surgical fixation using cannulated screws may provide increased preservation of deltoid function while offering good to excellent patient satisfaction. However, patients must be informed that a second operation may be required to remove symptomatic hardware. Surgeons must also appreciate that hardware removal involves an additional risk to the patient and cost to the health care system.

\section{Acknowledgements \\ None.}

\section{Funding}

None.

\section{Availability of data and materials}

Data sharing is not applicable to this article as no datasets were generated or analyzed during the current study.

\section{Authors' contributions}

JP and JBM performed the literature search and were mandated with the manuscript preparation. AK contributed to the drafting of the manuscript and revised the final manuscript critically. AJB and $J$ are the senior authors, and $J \mathrm{~L}$ is the corresponding author; both presented the systematic review idea, provided the background information, participated in the study design, and performed major revisions of the manuscript for important intellectual content. All authors have read and approved the final manuscript.
Ethics approval and consent to participate

Not applicable.

\section{Consent for publication}

Not required by the University of Calgary given the nature of the research project.

\section{Competing interests}

The authors declare that they have no competing interests.

\section{Publisher's Note}

Springer Nature remains neutral with regard to jurisdictional claims in published maps and institutional affiliations.

\section{Author details}

${ }^{1}$ Department of Surgery, Section of Orthopaedic Surgery, University of Calgary, Calgary, Alberta, Canada. ${ }^{2}$ Clinic of Orthopaedics and Paediatric Orthopaedics, Medical University of Łódź, Łódź, Poland.

Received: 20 September 2018 Accepted: 13 December 2018 Published online: 23 January 2019

\section{References}

1. Jehmlich S, Holovacs TF, Warner JJP. Treatment of the symptomatic os acromiale. Tech Shoulder Elb Surg. 2004;5(4):214-8.

2. Kurtz C, Humble B, Rodosky M, Sekiya J. Symptomatic os acromiale. J Am Acad Orthop Surg. 2006;14(1):12-9.

3. Boehm TD, Matzer M, Brazda D, Gohlke FE. Os acromiale associated with tear of the rotator cuff treated operatively. J Bone Joint Surg Br. 2003;85(4): 545-9.

4. Campbell PT, Nizlan NM, Skirving AP. Arthroscopic excision of os acromiale: effects on deltoid function and strength. Orthopedics. 2012;35(11):e1601-5.

5. Edelson JG, Zuckerman J, Hershkovitz I. Os acromiale: anatomy and surgical implications. J Bone Joint Surg Br. 1993;75(4):551-5.

6. Hutchinson MR, Veenstra MA. Arthroscopic decompression of shoulder impingement secondary to os acromiale. Arthroscopy. 1993;9(1):28-32.

7. Johnston PS, Paxton ES, Gordon V, Kraeutler MJ, Abboud JA, Williams GR. Os acromiale: a review and an introduction of a new surgical technique for management. Orthop Clin North Am. 2013:44(4):635-44.

8. Kawaguchi S, Fukuta S, Tsutsui T, Matsuura T, Suzue N, Hamada D, et al. Arthroscopic excision of unstable os acromiale associated with impingement syndrome: a case report. J Med Investig. 2016;63(1-2):131-4.

9. Pagnani MJ, Mathis CE, Solman CG. Painful os acromiale (or unfused acromial apophysis) in athletes. J Shoulder Elb Surg. 2006;15(4):432-5.

10. Wright RW, Heller MA, Quick DC, Buss DD. Arthroscopic decompression for impingement syndrome secondary to an unstable os acromiale. Arthroscopy. 2000;16(6):595-9.

11. Abboud JA, Silverberg D, Pepe M, Beredjiklian PK, lannotti JP, Williams GR, et al. Surgical treatment of os acromiale with and without associated rotator cuff tears. J Shoulder Elb Surg. 2006;15(3):265-70.

12. Atinga M, Gregor R, Selvaraj KM, Hong TF. Os acromiale open reduction and internal fixation: a review of iliac crest autogenous bone grafting and local bone grafting. J Shoulder Elb Surg. 2018;27(6):1030-6.

13. Atoun E, van Tongel A, Narvani A, Rath E, Sforza G, Levy O. Arthroscopically assisted internal fixation of the symptomatic unstable os acromiale with absorbable screws. J Shoulder Elb Surg. 2012;21(12):1740-5.

14. Barbier O, Block D, Dezaly C, Sirveaux F, Mole D. Os acromiale, a cause of shoulder pain, not to be overlooked. Orthop Traumatol Surg Res. 2013;99(4): 465-72.

15. Bedi A, Rodeo SA. Os acromiale as a cause for shoulder pain in a competitive swimmer: a case report. Sports Health. 2009;1(2):121-4.

16. Beliën H, Biesmans $H$, Steenwerckx A, Bijnens E, Dierickx C. Prebending of osteosynthesis plate using 3D printed models to treat symptomatic os acromiale and acromial fracture. J Exp Orthop. 2017:4(1):34.

17. Hertel R, Windisch W, Schuster A, Ballmer FT. Transacromial approach to obtain fusion of unstable os acromiale. J Shoulder Elb Surg. 1998;7(6):606-9.

18. Ryu RK, Fan RS, Dunbar WH. The treatment of symptomatic os acromiale. Orthopedics. 1999;22(3):325-8.

19. Sahajpal D, Strauss EJ, Ishak C, Keyes JMO, Joseph G, Jazrawi LM. Surgical management of os acromiale: a case report and review of the literature. Bull NYU Hosp Jt Dis. 2007;65(4):312-6. 
20. Satterlee CC. Successful osteosynthesis of an unstable mesoacromion in 6 shoulders: a new technique. J Shoulder Elb Surg. 1999;8(2):125-9.

21. Warner JJP, Beim GM, Higgins L. The treatment of symptomatic os acromiale. J Bone Joint Surg. 1998;80(9):1320-6.

22. Harris JD, Griesser MJ, Jones GL. Systematic review of the surgical treatment for symptomatic os acromiale. Int J Shoulder Surg. 2011;5(1):9-16.

23. Moher D, Liberati A, Tetzlaff J, Altman DG, PRISMA Group. Preferred reporting items for systematic reviews and meta-analyses: the PRISMA statement. PLoS Med. 2009;6(7):e1000097. https://doi.org/10.1371/journal. pmed.1000097.

24. Neer CS 2nd. Anterior acromioplasty for the chronic impingement syndrome in the shoulder. J Bone Joint Surg Am. 1972;54(1):41-50.

25. Bosley RC. Total acromionectomy. J Bone Joint Surg Am. 1991;73(7):961-8.

26. Wylie JD, Beckmann JT, Granger E, Tashjian RZ. Functional outcomes assessment in shoulder surgery. World J Orthop. 2014:5(5):623-33.

27. Holmgren T, Oberg B, Adolfsson L, Bjornsson Hallgren H, Johansson K Minimal important changes in the Constant-Murley score in patients with subacromial pain. J Shoulder Elb Surg. 2014;23(8):1083-90.

Ready to submit your research? Choose BMC and benefit from:

- fast, convenient online submission

- thorough peer review by experienced researchers in your field

- rapid publication on acceptance

- support for research data, including large and complex data types

- gold Open Access which fosters wider collaboration and increased citations

- maximum visibility for your research: over $100 \mathrm{M}$ website views per year

At $\mathrm{BMC}$, research is always in progress.

Learn more biomedcentral.com/submissions 